\title{
Dental Bonding Agent: Allergy Contact Dermatitis: Report of 3 Cases
}

\section{Zeina Berri', Mohammed Alshehri ${ }^{2}$, Norman} Firth $^{3}$ and Omar Kujan ${ }^{3 *}$

${ }^{1}$ Department of Oral Medicine and Diagnostic Sciences, Al-Farabi College for Dentistry and Nursing, Al-Farabi Colleges, Saudi Arabia

${ }^{2}$ Department of Dentistry, College of Medicine and University Hospitals, King Saud University, Saudi Arabia ${ }^{3}$ School of Dentistry, The University of Western Australia, Australia

*Corresponding author: Omar Kujan, School of Dentistry, The University of Western Australia, M512, 17 Monash Avenue, Nedlands,WA6009, Australia

Received: July 04, 2017; Accepted: August 10, 2017; Published: September 04, 2017

\section{Introduction}

The recent advances in the dental adhesive materials have transformed the scope of current dental practice, also driven by the huge demands for aesthetic solutions $[1,2]$. Therefore, dental professionals are now heavily exposed to the use of these advanced adhesives during their daily routine work [3]. Almost all types of dental bonding agents contain (Meth) acrylates [4].

Allergic contact dermatitis (ACD) is known as a noninfectious inflammatory disease of the skin characterised by the delayed hypersensitivity reactions that is known as type IV T-cell-mediated hypersensitivity reaction [5]. Several materials in dentistry including products containing (Meth) acrylates are well-known for provoking allergic reactions [6]. It is estimated that $5-10 \%$ of all ACD reports in dental professionals are due to contact with (Meth) acrylates [7]. We report three cases of ACD in dental interns due to the use of dental bonding agent containing (Meth) acrylates during a period of six months. The purpose of this case report is to promote the awareness of the risks of dealing with materials containing allergens such as (Meth) acrylates despite wearing latex or vinyl hand gloves.

\section{Case Presentation}

Three different cases have been reported at Al-Farabi Colleges for Dentistry and Nursing, Riyadh, Saudi Arabia due to dental bonding agent contact with the skin during the month of March 2015. The bonding agent used was Natural Bond DE (DFL INDÚSTRIA E COMÉRCIO S/A, Rio de Janeiro, Brazil).

Dental Interns were performing operative dentistry Class I and Class II restorations with composite resin. During the procedure, bonding agents are used to bond the composite resin to the tooth structure micromechanically. The interns were practicing all standard measures of infection control including gloves and maintaining cleanliness of the working area. During the procedure, the bonding agent came in contact with the gloves for around 20-40 minutes until the procedure was completed. All three interns were healthy with no history of allergies to any drug or food.

\section{Case 1}

A 23-year-old female dental intern, who used vinyl gloves to perform a dental restoration for the patient, experienced itching and redness of the dorsum of her left hand when she removed her gloves. A week following the initial injury at the beginning of March 2015, signs and symptoms of eczematous rash started evolving: elevated dark red papules in an area of redness, rashes, and pruritus of the area (Figure 1A). She didn't develop rashes or other lesions elsewhere. The lesions resolved after using topical corticosteroids for two weeks. A follow-up examination after two months revealed no signs of the previously reported lesions (Figure 1B).

\section{Case 2}

A 31-year-old male dental intern, who has used latex powder gloves during mid April 2015 to perform an operative dental procedure, developed redness and burning of his right fingers. The thumb was affected the most. After two days, the thumb's skin sloughed with moderate pain and bleeding lasting five days (Figure 2A, B). He had no rash elsewhere. Topical corticosteroid creams and Vaseline cream were used to relieve the pain and initiate healing. After two weeks, his thumb was affected again yet healing only took
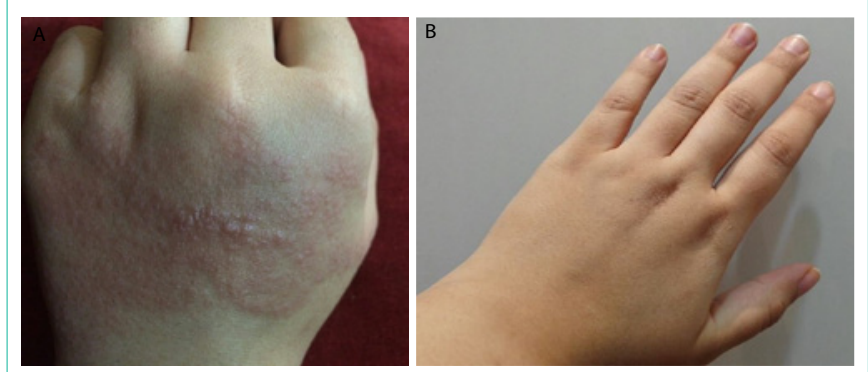

Figure 1: (A) Eczematous reaction on the dorsum of the left hand (Case 1), (B): Recovery follow-up of the dorsum of the left hand after 2 months (Case 1).
Austin J Dent - Volume 4 Issue 6 - 2017

ISSN : 2381-9189 | www.austinpublishing group.com

Kujan et al. (C) All rights are reserved
Citation: Berri Z, Alshehri M, Firth N and Kujan O. Dental Bonding Agent: Allergy Contact Dermatitis: Report of 3 Cases. Austin J Dent. 2017; 4(6): 1089 

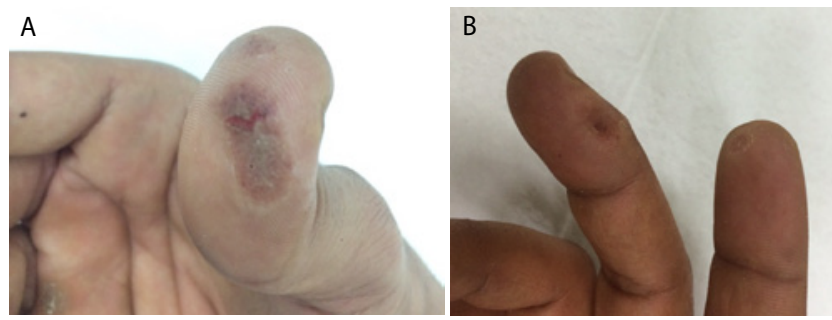

Figure 2: Slough reaction on the right fingers (Case 2); $(A)$ The thumb is the most affected, (B) The index and middle fingers.
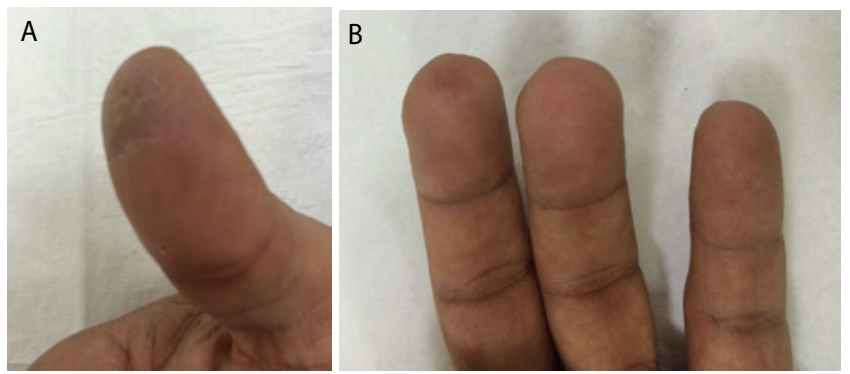

Figure 3: Recovery follow-up of right fingers (Case 2) after two months (Healing scarring); (A) The thumb, (B) the index and middle fingers.

four days. After four weeks from the first injury, there was complete healing with a hardened scar on the skin (Figure 3A, B).

\section{Case 3}

A 25-year-old female dental intern presented with a one week history of minor redness and itching on the dorsal skin surface of her right hand during June 2015. She was performing an operative composite procedure when bonding material contaminated her powder free latex gloves. As she was aware of the recent adverse reactions experienced by her colleagues, she replaced her gloves as soon as she noticed the contamination, which was about twenty minutes after starting the bonding step. This may explain why she only developed a minor lesion. She applied topical corticosteroids creams for a few days and the signs and symptoms disappeared (Figure 4). She also had no rash elsewhere.

\section{Patch testing}

On the development of these adverse reactions, an incident report was completed and the affected dental interns were seen by the occupational health physician who referred them to the dermatologists for further investigations. The three affected dental interns were patch-tested with the British baseline series and a dental/ (meth) acrylates (MA-1000) series (Chemotechnique Diagnostics, Modemgaton, Sweden) applied to the back using Finn Chambers on Scanpor tape (Acatavis, Norway). Table 1 shows the positive findings of the patch testing for all reported cases.

\section{Discussion}

Latex allergy of the gloves was excluded by the patch testing and by the fact that all affected dental interns with ACD developed similar pathological processes using different types of gloves: vinyl and latex gloves (powdered and powder free gloves). The patch testing confirmed the bonding agent as the causative factor for

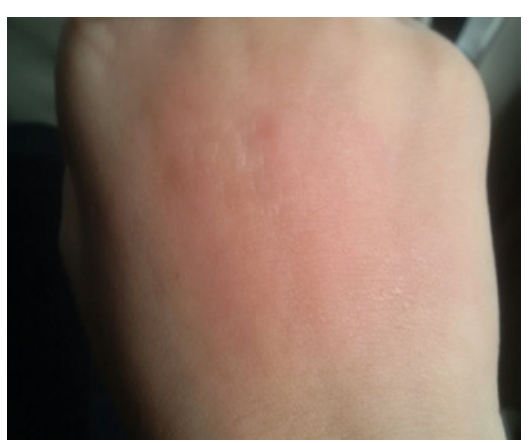

Figure 4: Erythematous plaque on the dorsum of the left hand (Case 3).

inducing the ACD events despite the presence of the barrier gloves. It is possible other chemicals in the bonding bottle have contributed to the development of irritation and itchy sensation. However, there is evidence that (Meth) acrylates in bonding agents can cause ACD in dental professionals $[7,8]$. The primary manifestation of (Meth) acrylates related ACD is eczematous rash $[6,7,9,10]$. In a Swedish study, $22 \%$ of the dental personnel patients had positive reactions to (Meth) acrylates [9]. The most frequent ACD reactions in the (Meth) acrylates series are reported with 2-HEMA (2-hydroxyethyl methacrylate), EDGMA (ethylene glycol dimethacrylate) and MMA (methyl methacrylate) [9]. Consistent with other reports, our case reports showed a positive reaction to 2-HEMA in all three cases. Surprisingly, TREGDMA (trimethylene glycol dimethacrylate) also was associated with a positive relatively late response on day four and five. TREGDMA is not as frequent as 2-HEMA [9], but in our cases, it was the most frequent alongside with 2-HEMA. BIS-MA (Bisphenol-A dimethacrylate) was only positive in one case.

When we obtained a detailed history of the cases from the affected dental interns, there was clearly a misconception that latex gloves would protect them. The interns' furthermost thought behind the cause of these reactions was an allergic response to the bonding agent. Despite the fact that the safety data sheet of the bonding agent and other similar materials that has (Meth) acrylates in its composition have a general statement on the use precautions. It didn't state clearly the potential ACD symptoms. Arguably, using a double gloving technique has been suggested to help maximizing the protection from allergen chemicals [8]. An important factor that we think has contributed to the development of these ACD events is the time of exposure. In two of the reported cases 40 minutes elapsed before the affected individuals were aware of the contamination of the gloves with the bonding agent. This may explain why they have developed severe symptoms while the third case had mild redness and itchy skin surface that lasted for less than week as she noticed the contamination earlier and replaced her gloves after washing the hands with water. Presumably interns take longer to do procedures than experienced dentists and therefore spend a long time polishing the restoration after curing.

Prevention is better than cure. Dental health care team members are vigilant to the potential allergy risk to latex (natural rubber latex) due to the awareness campaigns [10]. However, there is a long list of the dental chemicals that have allergen potency that personnel should be aware of when using [10]. 


\section{Conclusion}

(Meth) acrylates in bonding agents and other dental restorative materials have the potential risk of inducing allergic contact dermatitis when there is direct or indirect contact with skin and it is, therefore, important to increase the awareness of such risk among the dental professional to help prevent ACD and establishing a correct definitive diagnosis and facilitate appropriate immediate management.

\section{References}

1. Ikemura K, Endo T. A review of our development of dental adhesives--effects of radical polymerization initiators and adhesive monomers on adhesion. Dent Mater J. 2010; 29: 109-121.

2. Tay FR, Pashley DH. Dental adhesives of the future. J Adhes Dent. 2002; 4: $91-103$.

3. Heintze SD, Zimmerli B. Relevance of in vitro tests of adhesive and composite dental materials. A review in 3 parts. Part 3: in vitro tests of adhesive systems. Schweiz Monatsschr Zahnmed. 2011; 121: 1024-1040.

4. Milia E, Cumbo E, Cardoso RJ, Gallina G. Current dental adhesives systems. A narrative review. Curr Pharm Des. 2012; 18: 5542-5552.
5. Martin SF. Immunological mechanisms in allergic contact dermatitis. Curr Opin Allergy Clin Immunol. 2015; 15: 124-130.

6. Syed M, Chopra R, Sachdev V. Allergic Reactions to Dental Materials-A Systematic Review. J Clin Diagn Res. 2015; 9: ZE04-9.

7. Sanchez-Perez J, Gonzalez-Arriba A, Goiriz R, Garcia-Diez A. Occupational allergic contact dermatitis to acrylates and methacrylates. Contact Dermatitis. 2008; 58: 252-254

8. Prasad Hunasehally RY, Hughes TM, Stone NM. Atypical pattern of (meth) acrylate allergic contact dermatitis in dental professionals. Br Dent J. 2012 213: $223-224$

9. Wrangsjo K, Swartling C, Meding B. Occupational dermatitis in denta personnel: contact dermatitis with special reference to (meth) acrylates in 174 patients. Contact Dermatitis. 2001; 45: 158-163.

10. Hamann CP, Rodgers PA, Sullivan K. Allergic contact dermatitis in denta professionals: effective diagnosis and treatment. J Am Dent Assoc. 2003; 134: 185-194.
Austin J Dent - Volume 4 Issue 6 - 2017

ISSN : 2381-9189 | www.austinpublishing group.com

Kujan et al. (C) All rights are reserved
Citation: Berri Z, Alshehri M, Firth N and Kujan O. Dental Bonding Agent: Allergy Contact Dermatitis: Report of 3 Cases. Austin J Dent. 2017; 4(6): 1089 